\title{
Risk Factors for Predicting Hypoxia in Adult Patients Undergoing Bronchoscopy under Sedation
}

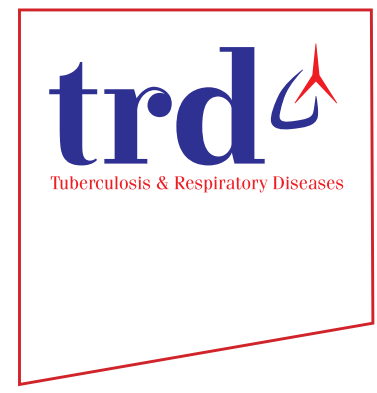

\author{
Ji Soo Choi, M.D. ${ }^{1}{ }^{(1)}$, Eun Hye Lee, M.D., Ph.D. ${ }^{1}$, Sang Hoon Lee, M.D., Ph.D. ${ }^{2}$, Ah Young Leem, \\ M.D., Ph.D. ${ }^{2}$, Kyung Soo Chung, M.D. ${ }^{2}$, Song Yee Kim, M.D., Ph.D. ${ }^{2}$, Ji Ye Jung, M.D., Ph.D. ${ }^{2}$, Young \\ Ae Kang, M.D., Ph.D. ${ }^{2}$, Moo Suk Park, M.D., Ph.D. ${ }^{2}$, Joon Chang, M.D., Ph.D. ${ }^{2}$ and Young Sam Kim, \\ M.D., Ph.D. ${ }^{2}$ (i) \\ ${ }^{1}$ Division of Pulmonology, Allergy and Critical Care Medicine, Department of Internal Medicine, Yongin Severance Hospital, \\ Yonsei University College of Medicine, Yongin, ${ }^{2}$ Division of Pulmonology, Department of Internal Medicine, Severance \\ Hospital, Yonsei University College of Medicine, Seoul, Korea
}

Background: Flexible bronchoscopy is one of the essential procedures for the diagnosis and treatment of pulmonary diseases. The purpose of this study was to identify the risk factors associated with the occurrence of hypoxia in adults undergoing flexible bronchoscopy under sedation.

Methods: We retrospectively analyzed 2,520 patients who underwent flexible bronchoscopy under sedation at our tertiary care university hospital in South Korea January 1, 2013-December 31, 2014. Hypoxia was defined as more than 5\%-point reduction in the baseline percutaneous oxygen saturation $\left(\mathrm{SpO}_{2}\right)$ or $\mathrm{SpO}_{2}<90 \%$ for $>1$ minute during the procedure.

Results: The mean age was $64.7 \pm 13.5$, and 565 patients developed hypoxia during the procedure. The mean sedation duration and midazolam dose for sedation were 31.1 minutes and $3.9 \mathrm{mg}$, respectively. The bivariate analysis showed that older age, a low forced expiratory volume in one second $\left(\mathrm{FEV}_{1}\right)$, use of endobronchial ultrasound, the duration of sedation, and the midazolam dose were associated with the occurrence of hypoxia during the procedure, while the multivariate analysis found that age $>60$ (odds ratio [OR], 1.32), a low $\mathrm{FEV}_{1}(\mathrm{OR}, 0.99$ ), and a longer duration of sedation (>40 minutes; OR, 1.33) were significant risk factors.

Conclusion: The findings suggest that patients older than age 60 and those with a low $\mathrm{FEV}_{1}$ tend to develop hypoxia during the bronchoscopy under sedation. Also, longer duration of sedation ( $>40$ minutes) was a significant risk factor for hypoxia.

Keywords: Bronchoscopy; Hypoxia; Risk Factors

Address for correspondence: Young Sam Kim, M.D., Ph.D.

Division of Pulmonology, Department of Internal Medicine, Severance Hospital, Yonsei University College of Medicine, 50-1 Yonsei-ro, Seodaemun-gu, Seoul 03722, Korea

Phone: 82-2-2228-1971, Fax: 82-2-393-6884, E-mail: ysamkim@yuhs.ac

Received: Jan. 17, 2020, Revised: May. 9, 2020, Accepted: Jul. 9, 2020, Published online: Jul. 9, 2020

(c) It is identical to the Creative Commons Attribution Non-Commercial License (http://creativecommons.org/licenses/by-nc/4.0/). 


\section{Introduction}

Flexible bronchoscopy is one of the most important procedures for diagnosis and treatment of pulmonary disease ${ }^{1}$. Bronchoscopy is also essential for mediastinal lymph node examination during nodal staging in patients with lung cancer $^{2-5}$. For better patient tolerance, bronchoscopists can choose to perform the procedure under sedation ${ }^{6,7}$. However, bronchoscopy under sedation is not easily performed in many hospitals because of the risk of several complications ${ }^{1,8}$, even though bronchoscopy itself is generally considered a safe procedure? Complications of bronchoscopy include bleeding, pneumothorax, fever, infection, and cardiac arrhythmia ${ }^{10-12}$. Although oxygen supplementation is routinely provided, hypoxia is a frequent event during bronchoscopy, particularly when sedation is used ${ }^{13-15}$. It is generally transient and resolves instantly; however, the clinician should consider terminating the procedure in cases where hypoxia persists for $>1$ minute $^{1}$. Several studies have reported the risk factors associated with hypoxia during bronchoscopy for foreign body removal in children ${ }^{16,17}$. The findings of those studies indicated that the patient's age and procedure duration were associated with the occurrence of hypoxia during bronchoscopy ${ }^{16,17}$. However, few studies have reported the risk factors for predicting hypoxia in elderly patients undergoing bronchoscopy under sedation. Accordingly, the aim of this study was to identify the risk factors associated with hypoxia during flexible bronchoscopy under sedation in adult patients.

\section{Materials and Methods}

\section{Study design}

We retrospectively analyzed 3,508 patients aged $>19$ years who underwent flexible bronchoscopy under sedation at our tertiary care university hospital in South Korea between January 1, 2013 and December 31, 2014. Patients who underwent bronchoscopy without sedation $(\mathrm{n}=451)$ or with intubation ( $\mathrm{n}=537$ ) were excluded (Figure 1).

We collected all relevant data associated with bronchoscopy under sedation, including baseline characteristics, pulmonary function test (PFT) results, echocardiography findings, and chest computed tomography (CT) findings just before the procedure in order to evaluate their associations with the occurrence of hypoxia during the procedure. Several factors associated with the bronchoscopy procedure, including the type of procedure, durations of the procedure and sedation, doses of sedative drugs (midazolam and fentanyl), and diameter of the bronchoscope, were also reviewed. The institutional review board (IRB 4-2019-0274) of Severance Hospital approved this retrospective study and waived the need for informed consent.

\section{Procedure and sedation}

Bronchoscopy was performed under topical and intravenous anesthesia with spontaneous breathing. Before the procedure, $4 \%$ lidocaine spray was applied in the oral cavity for topical anesthesia. Sedative drugs, including midazolam $(0.03-0.05 \mathrm{mg} / \mathrm{kg}$ ) and $50 \mu \mathrm{g}$ of fentanyl, were administered just before the procedure at the discretion of the bronchoscopist. With the patient in the supine position, the bronchoscope was inserted through the oral or nasal cavity depending on the patient's condition. Then, $4 \%$ lidocaine was applied to the vocal cords, main carina, and both main bronchi through a channel of the bronchoscope. The target level of sedation was moderate so that patients could purposefully respond to verbal commands while maintaining a functional airway and cardiovascular function. The bronchoscopist used additional midazolam or fentanyl doses to maintain the level of sedation during the procedure.

Hypoxia was defined as more than 5\%-point reduction in the baseline percutaneous oxygen saturation $\left(\mathrm{SpO}_{2}\right)$ or $\mathrm{SpO}_{2}$ $<90 \%$ for $>1$ minute during the procedure. The oxygen of $4 \mathrm{~L} /$ min was applied through a nasal cannula to all patients before the bronchoscopy was started, and oxygen supplement was increased to $8 \mathrm{~L} / \mathrm{min}$ in case of desaturation. If oxygen desaturation was not recovered despite maximal oxygen support, the procedure was stopped according to the decisions of bronchoscopist. Electrocardiograms and vital signs, including blood pressure, heart rate, and oxygen saturation, were continuously monitored during the procedure.

\section{Statistical analysis}

All data were statistically analyzed using SAS version 9.2 (SAS Institute Inc., Cary, NC, USA). Categorical variables are presented as numbers with percentages and were analyzed

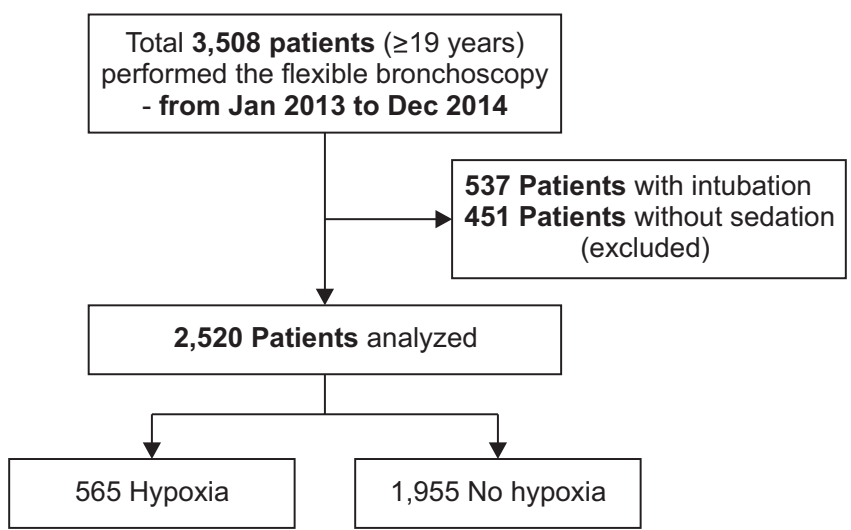

Figure 1. Flow chart of the inclusion and the exclusion procedures for the study. A total of 3,508 patients were enrolled, and 2,520 were included in the analysis. 
using the chi-squared test. Continuous variables are presented as means \pm standard deviations and were evaluated using Student's t-test. Multivariate logistic regression analysis was used to evaluate the association between risk factors and the development of hypoxia during the procedure, with the results presented as odds ratios (ORs) with 95\% confidence intervals (CIs). A p-value of $<0.05$ was considered statistically significant.

\section{Results}

\section{Baseline characteristics of the study population}

The study sample comprised of 1,585 men (62.9\%) and 935 women $(37.1 \%)$. A total of $1,654(65.6 \%)$ patients were $>60$ years old, with a mean age of $64.7 \pm 13.5$ years. With regard to the smoking status, 1,178 patients $(46.7 \%)$ were never-smokers and 1,342 (53.2\%) were ever-smokers. The most common underlying disease was hypertension (36.7\%).
Tables 1 and 2 show the baseline characteristics of patients according to the occurrence of hypoxia during bronchoscopy under sedation. In total, 565 of the 2,520 patients (22.4\%) developed hypoxia. The initial saturation level was not different between the two groups. The proportion of patients aged $>60$ years was significantly higher in the desaturation group than in the no desaturation groups ( $\mathrm{p}=0.003)$. There were no between-group differences in terms of sex, the smoking status, the history of smoking (pack-years), and prevalence of underlying diseases. Patients with hypoxia presented a significantly lower forced expiratory volume in 1 second $\left(\mathrm{FEV}_{1}\right)$ just before the procedure $(\mathrm{p}=0.049)$ (Table 2). However, the forced vital capacity (FVC), $\mathrm{FEV}_{1} / \mathrm{FVC}$ ratio, and diffusing capacity of the lung for carbon monoxide $\left(\mathrm{DL}_{\mathrm{CO}}\right)$ were comparable between groups. Finally, there were no significant between-group differences in terms of chest CT and echocardiography findings.

Table 1. Baseline characteristics of patients stratified according to the occurrence of desaturation during flexible bronchoscopy under sedation

\begin{tabular}{|c|c|c|c|}
\hline Variable & No desaturation $(n=1,955)$ & Desaturation $(n=565)$ & p-value \\
\hline \multicolumn{4}{|l|}{ Age, yr } \\
\hline$\leq 60$ & $701(35.9)$ & $165(29.2)$ & \\
\hline$>60$ & $1,254(64.1)$ & $400(70.8)$ & 0.003 \\
\hline Male sex & $1,236(63.2)$ & $349(61.7)$ & 0.529 \\
\hline BMI, $\mathrm{kg} / \mathrm{m}^{2}$ & $22.4 \pm 3.7$ & $22.1 \pm 3.6$ & 0.072 \\
\hline \multicolumn{4}{|l|}{ Smoking status } \\
\hline Never-smoker & $910(46.5)$ & $268(47.4)$ & 0.234 \\
\hline Ever-smoker & $1,045(53.5)$ & $297(52.6)$ & \\
\hline History of smoking, pack-years & $35.2 \pm 22.2$ & $34.7 \pm 21.3$ & 0.737 \\
\hline \multicolumn{4}{|l|}{ Underlying disease } \\
\hline Hypertension & $702(35.9)$ & $222(39.3)$ & 0.142 \\
\hline Diabetes mellitus & $382(19.5)$ & $123(21.8)$ & 0.243 \\
\hline Chronic hepatitis & $70(3.6)$ & $16(2.8)$ & 0.388 \\
\hline Pulmonary tuberculosis & $326(16.7)$ & $99(17.5)$ & 0.636 \\
\hline Cardiovascular disease* & $189(9.7)$ & $54(9.6)$ & 0.938 \\
\hline Neuromuscular disease $^{\dagger}$ & $92(4.7)$ & $20(3.5)$ & 0.236 \\
\hline Chronic kidney disease & $47(2.4)$ & $16(2.8)$ & 0.566 \\
\hline Malignancy $^{*}$ & $476(24.4)$ & $159(28.1)$ & 0.067 \\
\hline Chronic obstructive pulmonary disease & $103(5.3)$ & $35(6.2)$ & 0.394 \\
\hline
\end{tabular}

Values are presented as number (\%) or mean \pm standard deviation.

*Cardiovascular disease includes coronary artery occlusive disease, arrhythmia, valvular heart disease, and congestive heart failure. "Neuromuscular disease includes cerebral infarction, cerebral hemorrhage, Alzheimer's disease, Parkinson's disease, epilepsy, and brain tumor. "Malignancy includes solid malignancy and hematological malignancy.

BMI: body mass index. 
Table 2. Comparison of various clinical and procedural findings according to the presence or absence of desaturation during flexible bronchoscopy under sedation

\begin{tabular}{|c|c|c|c|}
\hline Variable & No desaturation $(n=1,955)$ & Desaturation $(n=565)$ & p-value \\
\hline \multicolumn{4}{|l|}{ Pulmonary function test } \\
\hline FVC, \% predicted & $84.5 \pm 21.3$ & $82.2 \pm 20.1$ & 0.063 \\
\hline $\mathrm{FEV}_{1}, \%$ predicted & $87.3 \pm 24.2$ & $84.5 \pm 23.4$ & 0.049 \\
\hline $\mathrm{FEV}_{1} / \mathrm{FVC}$, predicted & $73.8 \pm 12.3$ & $73.0 \pm 12.4$ & 0.294 \\
\hline $\mathrm{DL}_{\mathrm{CO}}, \%$ & $91.0 \pm 25.8$ & $90.0 \pm 28.8$ & 0.625 \\
\hline \multicolumn{4}{|l|}{ Chest CT findings before procedure } \\
\hline Emphysema & $344(17.6)$ & $110(19.5)$ & 0.317 \\
\hline Ground-glass opacity or honeycombing & $154(7.9)$ & $50(8.9)$ & 0.463 \\
\hline Consolidation & $609(31.2)$ & $168(29.7)$ & 0.503 \\
\hline Pleural effusion & $249(12.8)$ & $79(14.0)$ & 0.448 \\
\hline Bronchiectasis in at least two lobes & $108(5.5)$ & $41(7.3)$ & 0.127 \\
\hline \multicolumn{4}{|l|}{ Echocardiography findings } \\
\hline $\mathrm{EF}, \%$ & $64.0 \pm 9.6$ & $63.1 \pm 10.9$ & 0.276 \\
\hline RVP, mm Hg & $31.2 \pm 12.6$ & $32.3 \pm 12.7$ & 0.340 \\
\hline \multicolumn{4}{|l|}{ Type of procedure } \\
\hline Bronchoalveolar lavage & $68(3.48)$ & $18(3.2)$ & 0.741 \\
\hline TBLB & $1,011(51.7)$ & $293(52.0)$ & 0.921 \\
\hline EBUS-TBNA & $605(31.0)$ & $216(38.3)$ & 0.001 \\
\hline \multicolumn{4}{|l|}{ Factor associated with the procedure } \\
\hline Clinician's experience in the procedure, yr & $2.24 \pm 1.42$ & $2.31 \pm 1.37$ & 0.299 \\
\hline \multicolumn{4}{|l|}{ Duration of sedation, min } \\
\hline$<20$ & $561(28.7)$ & $94(16.6)$ & \\
\hline $20-30$ & $526(27.0)$ & $125(22.1)$ & \\
\hline $30-40$ & $371(19.0)$ & $114(20.2)$ & $<0.001$ \\
\hline$>40$ & $497(25.4)$ & $232(41.1)$ & \\
\hline Dose of midazolam, mg & $3.84 \pm 1.39$ & $3.98 \pm 1.54$ & 0.046 \\
\hline Dose of fentanyl, mg & $47.7 \pm 14.2$ & $48.4 \pm 12.9$ & 0.287 \\
\hline Bronchoscope with a large diameter & $1,506(77.4)$ & $431(77.0)$ & 0.848 \\
\hline
\end{tabular}

Values are presented as mean \pm standard deviation or number (\%) unless otherwise indicated.

FVC: forced vital capacity; $\mathrm{FEV}_{1}$ : forced expiratory volume in 1 second; $\mathrm{DL}_{\mathrm{CO}}$ : diffusing capacity; $\mathrm{CT}$ : computed tomography; EF: ejection fraction; RVP: right ventricular pressure; TBLB: transbronchial lung biopsy; EBUS-TBNA: endobronchial ultrasound-guided transbronchial needle aspiration.

\section{Procedural factors associated with hypoxia development}

In total, 86 patients (3.4\%) underwent bronchoscopy with bronchoalveolar lavage (BAL), while 1,304 (51.7\%) and 821 (32.6\%) patients underwent transbronchial lung biopsy and endobronchial ultrasound-guided transbronchial needle aspiration (EBUS-TBNA). The mean duration of sedation and mean dose of midazolam for sedation were $31.1 \pm 17.3$ minurwa and $3.9 \pm 2.4 \mathrm{mg}$. Table 2 shows the factors associated with bronchoscopy according to the occurrence of hypoxia during the procedure. The proportion of patients who underwent EBUS-TBNA was significantly higher in the desaturation group than in the no desaturation group $(\mathrm{p}=0.001)$. There were no significant between-group differences for the other procedures. Moreover, the duration of sedation was significantly longer $(p<0.001)$ while the midazolam dose was significantly higher $(\mathrm{p}=0.046)$ in the desaturation group than in the no desaturation group. There were no between-group differences in terms of the fentanyl dose, procedure duration, and 
Table 3. Multivariate analysis for predictors of hypoxia during flexible bronchoscopy under sedation

\begin{tabular}{|lccc|}
\hline \multicolumn{1}{|c}{ Variable } & OR & 95\% CI & p-value \\
\hline Age, yr & & & \\
\hline Up to 60 & & & \\
\hline More than 60 & 1.322 & $1.007-1.734$ & 0.044 \\
\hline Low FEV , $_{1}$ predicted & 0.994 & $0.989-0.999$ & 0.013 \\
\hline EBUS-TBNA & & & \\
\hline Yes & 0.987 & $0.753-1.293$ & 0.924 \\
\hline No & & & \\
\hline Duration of sedation, min & & & \\
\hline$<20$ & & & \\
\hline 20-30 & & & \\
\hline 30-40 & & & 0.001 \\
\hline$>40$ & 1.329 & $1.179-1.499$ & \\
\hline Midazolam dose & 1.027 & $0.942-1.119$ & 0.550 \\
\hline
\end{tabular}

OR: odds ratio; CI: confidence interval; $\mathrm{FEV}_{1}$ : forced expiratory volume in one second; EBUS-TBNA: endobronchial ultrasound-guided transbronchial needle aspiration.

use of a bronchoscope with a large diameter.

We performed multivariate analysis to analyze factors that were significant in bivariate analysis, including age $>60$ years, low $\mathrm{FEV}_{1}$ in PFT, use of EBUS-TBNA, duration of sedation, and midazolam dose (Table 3 ). Age $>60$ years (OR, 1.32; 95\% CI, 1.007-1.734), a low FEV ${ }_{1}$ in PFT (OR, 0.99; 95\% CI, 0.9890.999 ), and a longer duration of sedation (>40 minutes; OR, 1.33; 95\% CI, 1.179-1.499) were significantly associated with the occurrence of hypoxia.

\section{Discussion}

The results of this study showed that an age of $>60$ years, a low $\mathrm{FEV}_{1}$, and a longer duration of sedation were significant predictors of the occurrence of hypoxia during bronchoscopy under sedation in adults.

Flexible bronchoscopy is an essential diagnostic and therapeutic procedure in respiratory medicine. However, it leads to coughing and discomfort in patients ${ }^{1}$. Sedation is used for not only surgery but also various other procedures ${ }^{8,18}$. Several patients are more comfortable undergoing endoscopy under sedation; therefore, gastrointestinal endoscopy is commonly performed under sedation ${ }^{19-21}$. In addition, there have been efforts to perform bronchoscopy under sedation, which is reportedly associated with increased patient and clinician satisfaction $^{6,22}$. Thus, bronchoscopy under sedation is generally recommended in the absence of any contraindications ${ }^{1,23}$.

However, several centers still do not use sedation during bronchoscopy because of the risk of side effects. Complications of bronchoscopy include bleeding, pneumothorax, fever, hypoxia, and cardiac arrhythmia ${ }^{10-12}$, and hypoxia is a common event during bronchoscopy under sedation. In most cases, it is transient and resolves quickly ${ }^{24-26}$, although the bronchoscopist may need to stop the examination and increase the oxygen supply or wake the patient during the procedure. If the hypoxia does not resolve, the procedure should be terminated ${ }^{27}$. A previous study reported that bronchoscopy under sedation provides comfort to the patient and bronchoscopist $^{28}$, while other studies evaluated drugs that are more effective for sedation during the procedure ${ }^{29,30}$. However, few studies have analyzed the risk factors for hypoxia during bronchoscopy under sedation in adults ${ }^{15,31}$, although some have analyzed these risk factors for pediatric patients undergoing foreign body removal via bronchoscopy ${ }^{16,17}$. Determination of these risk factors for adult patients is important because of the widespread use of bronchoscopy, including interventional bronchoscopy $^{7}$, and the increase in the number of elderly patients undergoing the procedure ${ }^{32}$.

Silvestri et al. ${ }^{33}$ evaluated the use of fospropofol disodium for sedation in patients undergoing flexible bronchoscopy and reported that hypoxia was more frequent in older patients than in younger patients, although the difference was not significant. In the present study, an age of $>60$ years was found to be significantly associated with the occurrence of hypoxia during bronchoscopy under sedation. Another significant risk factor was a low $\mathrm{FEV}_{1}$. Jones and $\mathrm{O}^{\prime} \mathrm{Driscoll}^{24}$ also reported that the risk of desaturation during bronchoscopy was higher for patients with a lower $\mathrm{FEV}_{1}$, suggesting that those patients required oxygen supplementation during the procedure. Finally, Chen et al. ${ }^{17}$ reported that the longer duration of surgical procedure ( $>20$ minutes) was correlated with intraoperative hypoxemia in young patients undergoing rigid bronchoscopy. And, Bittencourt et al. ${ }^{16}$ had also resulted that a longer procedure time was vulnerable to a risk of hypoxemia in children. In our study result, we found that a longer duration of sedation ( $>40$ minutes) was a significant risk factor for hypoxia.

In previous studies, bronchoscopy with BAL was related to the occurrence of hypoxia during the procedure ${ }^{34,35}$. This association was not observed in the present study, probably because only $3.4 \%$ patients underwent bronchoscopy with BAL. Therefore, additional studies in a larger number of patients are necessary to evaluate the association between bronchoscopy with BAL and hypoxia. Furthermore, there are several studies related to the risk of hypoxia during bronchoscopy in patients with severe chronic lung disease and heart failure ${ }^{36,37}$. However, in our study, there were no association between development of hypoxia and prevalence of underlying disease or results of chest CT and echocardiography. We only investigated the presence of underlying disease, so we could not reflect the severity of that disease. Therefore, further research about the risk of hypoxia during bronchoscopy with sedation 
according to the severity of the disease is needed.

Our study has several limitations. First was the retrospective, single-center design. Second, subjective symptoms that can affect the occurrence of hypoxia, such as dyspnea, cough, and sputum, were not investigated. Third, although we investigated the total sedation time, the actual procedure duration was difficult to record because our analysis was retrospective. Fourth, we could not investigate the history of obstructive sleep apnea (OSA), although patients with OSA might be vulnerable to develop hypoxia during procedure with sedation. Fifth, there is a statistically significant difference between $\mathrm{FEV}_{1} \%$ predicted and occurrence of hypoxia in our study. But the actual difference of is only $3 \%$ ( 87.3 vs. 84.5 ) between two groups. Most of the patients included in our study had normal lung function, and patients with less than $50 \%$ of predictive $\mathrm{FEV}_{1}$ values were only $4.8 \%$ of all patients. For this reason, these differences could not have clinically valuable meaning.

Nevertheless, this study also has its strengths. Our results were obtained for a large number of patients and can be used to predict the occurrence of hypoxia during bronchoscopy under sedation before the procedure. Thus, the bronchoscopist can evaluate the risk of hypoxia in advance and prepare any required devices, including a high-oxygen nasal cannula or noninvasive positive pressure ventilator, for patients exhibiting any of the risk factors. Maitre et al. ${ }^{38}$ and Heunks et al. ${ }^{39}$ reported that the use of a noninvasive positive pressure ventilator is useful during bronchoscopy in hypoxemic patients. Furthermore, Lucangelo et al. ${ }^{40}$ reported that a high-flow nasal interface could be effectively used in patients with mild respiratory dysfunction during bronchoscopy. This can reduce not only patient discomfort but also the burden on the bronchoscopist. However, further prospective studies are needed to validate our findings.

In conclusion, the results of this study suggest that age $>60$ years, a low $\mathrm{FEV}_{1}$, and a longer duration of sedation ( $>40 \mathrm{~min}-$ utes) are risk factors for hypoxia during bronchoscopy under sedation in adult patients. Therefore, patients with these risk factors should be prepared and cautioned about the complication before they undergo the procedure. Further prospective, multicenter studies are necessary to validate these findings and improve the safety of bronchoscopy under sedation.

\section{Authors' Contributions}

Conceptualization: Kim YS. Methodology: Choi JS, Kim YS. Formal analysis: Choi JS, Kim YS. Data curation: Choi JS, Kim YS. Investigation: Choi JS, Kim YS. Writing - original draft preparation: Choi JS, Kim YS. Writing - review and editing: Choi JS, Lee EH, Lee SH, Leem AY, Chung KS, Kim SY, Jung JY, Kang YA, Park MS, Chang J, Kim YS. Approval of final manuscript: all authors.

\section{Conflicts of Interest}

No potential conflict of interest relevant to this article was reported.

\section{Funding}

This study was supported by a faculty research grant from Yonsei University College of Medicine (6-2015-0068).

\section{References}

1. Du Rand IA, Blaikley J, Booton R, Chaudhuri N, Gupta V, Khalid S, et al. British Thoracic Society guideline for diagnostic flexible bronchoscopy in adults: accredited by NICE. Thorax 2013;68 Suppl 1:11-44.

2. Gomez M, Silvestri GA. Endobronchial ultrasound for the diagnosis and staging of lung cancer. Proc Am Thorac Soc 2009; 6:180-6.

3. Navani N, Nankivell M, Lawrence DR, Lock S, Makker H, Baldwin DR, et al. Lung cancer diagnosis and staging with endobronchial ultrasound-guided transbronchial needle aspiration compared with conventional approaches: an open-label, pragmatic, randomised controlled trial. Lancet Respir Med 2015;3:282-9.

4. Holty JE, Kuschner WG, Gould MK. Accuracy of transbronchial needle aspiration for mediastinal staging of non-small cell lung cancer: a meta-analysis. Thorax 2005;60:949-55.

5. Lilo MT, Allison DB, Younes BK, Cui M, Askin FB, Gabrielson E, et al. The critical role of EBUS-TBNA cytology in the staging of mediastinal lymph nodes in lung cancer patients: a correlation study with positron emission tomography findings. Cancer Cytopathol 2017;125:717-25.

6. Putinati S, Ballerin L, Corbetta L, Trevisani L, Potena A. Patient satisfaction with conscious sedation for bronchoscopy. Chest 1999;115:1437-40.

7. Jose RJ, Shaefi S, Navani N. Sedation for flexible bronchoscopy: current and emerging evidence. Eur Respir Rev 2013;22: $106-16$.

8. Leiten EO, Martinsen EM, Bakke PS, Eagan TM, Gronseth R. Complications and discomfort of bronchoscopy: a systematic review. Eur Clin Respir J 2016;3:33324.

9. Facciolongo N, Patelli M, Gasparini S, Lazzari Agli L, Salio M, Simonassi C, et al. Incidence of complications in bronchoscopy: multicentre prospective study of 20,986 bronchoscopies. Monaldi Arch Chest Dis 2009;71:8-14.

10. Stahl DL, Richard KM, Papadimos TJ. Complications of bronchoscopy: a concise synopsis. Int J Crit Illn Inj Sci 2015;5:18995.

11. Pereira W Jr, Kovnat DM, Snider GL. A prospective cooperative study of complications following flexible fiberoptic bron- 
choscopy. Chest 1978;73:813-6.

12. Jin F, Mu D, Chu D, Fu E, Xie Y, Liu T. Severe complications of bronchoscopy. Respiration 2008;76:429-33.

13. Albertini RE, Harrell JH 2nd, Kurihara N, Moser KM. Arterial hypoxemia induced by fiberoptic bronchoscopy. JAMA 1974;230:1666-7.

14. Matsushima Y, Jones RL, King EG, Moysa G, Alton JD. Alterations in pulmonary mechanics and gas exchange during routine fiberoptic bronchoscopy. Chest 1984;86:184-8.

15. Fang WF, Chen YC, Chung YH, Woon WT, Tseng CC, Chang $\mathrm{HW}$, et al. Predictors of oxygen desaturation in patients undergoing diagnostic bronchoscopy. Chang Gung Med J 2006; 29:306-12

16. Bittencourt PF, Camargos P, Picinin IF. Risk factors associated with hypoxemia during foreign body removal from airways in childhood. Int J Pediatr Otorhinolaryngol 2013;77:986-9.

17. Chen LH, Zhang X, Li SQ, Liu YQ, Zhang TY, Wu JZ. The risk factors for hypoxemia in children younger than 5 years old undergoing rigid bronchoscopy for foreign body removal. Anesth Analg 2009;109:1079-84.

18. Ni YL, Lo YL, Lin TY, Fang YF, Kuo HP. Conscious sedation reduces patient discomfort and improves satisfaction in flexible bronchoscopy. Chang Gung Med J 2010;33:443-52.

19. Lin OS. Sedation for routine gastrointestinal endoscopic procedures: a review on efficacy, safety, efficiency, cost and satisfaction. Intest Res 2017;15:456-66.

20. Radaelli F, Meucci G, Sgroi G, Minoli G; Italian Association of Hospital Gastroenterologists (AIGO). Technical performance of colonoscopy: the key role of sedation/analgesia and other quality indicators. Am J Gastroenterol 2008;103:1122-30.

21. Cohen LB, Wecsler JS, Gaetano JN, Benson AA, Miller KM, Durkalski V, et al. Endoscopic sedation in the United States: results from a nationwide survey. Am J Gastroenterol 2006; 101:967-74.

22. Hong KS, Choi EY, Park DA, Park J. Safety and efficacy of the moderate sedation during flexible bronchoscopic procedure: a systematic review and meta-analysis of randomized controlled trials. Medicine (Baltimore) 2015;94:e1459.

23. Wahidi MM, Jain P, Jantz M, Lee P, Mackensen GB, Barbour SY, et al. American College of Chest Physicians consensus statement on the use of topical anesthesia, analgesia, and sedation during flexible bronchoscopy in adult patients. Chest 2011;140:1342-50.

24. Jones AM, O'Driscoll R. Do all patients require supplemental oxygen during flexible bronchoscopy? Chest 2001;119:19069.

25. Grendelmeier P, Tamm M, Pflimlin E, Stolz D. Propofol sedation for flexible bronchoscopy: a randomised, noninferiority trial. Eur Respir J 2014;43:591-601.

26. Liao W, Ma G, Su QG, Fang Y, Gu BC, Zou XM. Dexmedetomi- dine versus midazolam for conscious sedation in postoperative patients undergoing flexible bronchoscopy: a randomized study. J Int Med Res 2012;40:1371-80.

27. Chhajed PN, Glanville AR. Management of hypoxemia during flexible bronchoscopy. Clin Chest Med 2003;24:511-6.

28. Hirose T, Okuda K, Ishida H, Sugiyama T, Kusumoto S, Nakashima M, et al. Patient satisfaction with sedation for flexible bronchoscopy. Respirology 2008;13:722-7.

29. Stolz D, Kurer G, Meyer A, Chhajed PN, Pflimlin E, Strobel W, et al. Propofol versus combined sedation in flexible bronchoscopy: a randomised non-inferiority trial. Eur Respir J 2009;34: 1024-30.

30. Clarkson K, Power CK, O'Connell F, Pathmakanthan S, Burke CM. A comparative evaluation of propofol and midazolam as sedative agents in fiberoptic bronchoscopy. Chest 1993;104:1029-31.

31. Kristensen MS, Milman N, Jarnvig IL. Pulse oximetry at fibreoptic bronchoscopy in local anaesthesia: indication for postbronchoscopy oxygen supplementation? Respir Med 1998; 92:432-7.

32. Hadique S, Jain P. Safety of bronchoscopy in elderly. Curr Geriatr Rep 2015;4:154-65.

33. Silvestri GA, Vincent BD, Wahidi MM. Fospropofol disodium for sedation in elderly patients undergoing flexible bronchoscopy. J Bronchology Interv Pulmonol 2011;18:15-22.

34. Gibson PG, Breit SN, Bryant DH. Hypoxia during bronchoalveolar lavage. Aust N Z J Med 1990;20:39-43.

35. Pirozynski M, Sliwinski P, Radwan L, Zielinski J. Bronchoalveolar lavage: comparison of three commonly used procedures. Respiration 1991;58:72-6.

36. Neuman Y, Koslow M, Matveychuk A, Bar-Sef A, Guber A, Shitrit D. Increased hypoxemia in patients with COPD and pulmonary hypertension undergoing bronchoscopy with biopsy. Int J Chron Obstruct Pulmon Dis 2015;10:2627-32.

37. Peacock AJ, Benson-Mitchell R, Godfrey R. Effect of fibreoptic bronchoscopy on pulmonary function. Thorax 1990;45:38-41.

38. Maitre B, Jaber S, Maggiore SM, Bergot E, Richard JC, Bakthiari $\mathrm{H}$, et al. Continuous positive airway pressure during fiberoptic bronchoscopy in hypoxemic patients: a randomized double-blind study using a new device. Am J Respir Crit Care Med 2000;162(3 Pt 1):1063-7.

39. Heunks LM, de Bruin CJ, van der Hoeven JG, van der Heijden HF. Non-invasive mechanical ventilation for diagnostic bronchoscopy using a new face mask: an observational feasibility study. Intensive Care Med 2010;36:143-7.

40. Lucangelo U, Vassallo FG, Marras E, Ferluga M, Beziza E, Comuzzi L, et al. High-flow nasal interface improves oxygenation in patients undergoing bronchoscopy. Crit Care Res Pract 2012;2012:506382. 